\title{
Are Past Adverse Pregnancy Outcomes Associated with Maternal Anxiety and Depressive Symptoms in a Sample of Currently Pregnant Women?
}

\author{
Amanuel Alemu Abajobir ${ }^{*}$, Rosa Alati ${ }^{1,2}$, Steve Kisely ${ }^{3,4}$, Jake Moses \\ Najman $^{1,5,6}$
}

\section{OPEN ACCESS}

Citation: Amanuel Alemu Abajobir, Rosa Alati, Steve Kisely, Jake Moses Najman. Are Past Adverse Pregnancy Outcomes Associated with Maternal Anxiety and Depressive Symptoms in a Sample of Currently Pregnant Women?. J Health Sci 2017;27(4):351.

http://dx.doi.org/10.4314/ejhs.v27i4.6

Received: December 24, 2016

Accepted: December 27, 2016

Published: July 1, 2017

Copyright: () 2017 Amanuel Alemu, et al. This is an open access article distributed under the terms of the Creative Commons Attribution License, which permits unrestricted use, distribution, and reproduction in any medium, provided the original author and source are credited.

Funding: Funding for this study was obtained from The National Health and Medical Research Council of Australia (NHMRC). There has been no funding provided by commercial and other interests. All decisions regarding study design and data analyses are made by the principal investigator.

Competing Interests: The authors

declare that this manuscript was approved

by all authors in its form and that no

competing interest exists.

Affiliation and Correspondence:

${ }^{1}$ School of Public Health, The

University of Queensland, Australia

${ }^{2}$ Centre for Youth Substance Abuse

Research, The University of

Queensland, Australia

${ }^{3}$ School of Medicine, University of Queensland, Australia

${ }^{4}$ Departments of Psychiatry, Community Health and Epidemiology,

Dalhousie University, Canada

${ }^{5}$ School of Social Sciences, The

University of Queensland, Australia

${ }^{6}$ Queensland Alcohol and Drug

Research and Education Centre, the

University of Queensland, Australia

"Email:amanuel.abajobir@uqconnect.ed u.au

\section{ABSTRACT}

BACKGROUND: There has been a great deal of concern about the mental health of women whose pregnancies involve miscarriage, termination of a pregnancy (ToP), child death or where a child has been given up for adoption. Despite this concern there has been remarkably little population-based research which has addressed the long-term consequences of pregnancy loss and child death. This study investigated the maternal mental health consequences of women whose pregnancies involve miscarriage, ToP, child death or where a child has been given up for adoption at two different time points, adjusting for socio-demographic characteristics and baseline mental health.

METHODS: The Mater-University of Queensland Study of Pregnancy is a prospective pre-birth cohort study. Women were recruited early in pregnancy over the period 1981 to 1983 at their first antenatal clinic visit (FCV). Women were interviewed again at the 14-year follow-up. Data from 4403 mothers were analysed using maternal reports of a prior history of giving a child up for adoption, miscarriage, ToP, and neonatal, infant and/or child deaths. Symptoms of maternal anxiety and depression were measured at FCV and the 14-year follow-up using the DelusionsSymptoms-States Inventory. We carried out logistic regression analysis using Stata 13. Odds ratios (ORs) with 95\% confidence intervals (CIs) were used to display the findings.

RESULTS: A prior miscarriage was associated with anxiety (adjusted OR $(A O R)=1.30 ; 95 \%$ CI: 1.10-1.66) and depressive $(A O R=1.70 ; 95 \%$ CI: 1.21-2.39) symptoms at the 14-year followup. Having had a neonatal, infant and/or child deaths was associated with symptoms of depression at 14-year follow-up (AOR $=2.12$; 95\% CI: 1.06-4.25).

CONCLUSION: The period after a child loss which involves a new pregnancy may be associated with relatively good mental health despite the fact that some mothers have experienced previous adverse pregnancy outcomes.

KEYWORDS: Women, anxiety, depression, adoption, miscarriage, termination of pregnancy, death of neonatal, infant and/or child 


\section{INTRODUCTION}

Despite widespread concerns about the negative mental health consequences of adverse pregnancy outcomes, the available evidence base is limited and inconsistent. The current literature is mixed and has been criticised for non-generalizability across all age ranges of women, brief periods of follow-ups, failure to control for pre-existing mental health problems and other confounders (1). There is a need for a well-designed (2) multi-wave prospective study with appropriate controls (2) reporting different domains of mental illnesses which are associated with a variety of adverse pregnancy outcomes (3).

There are a number of outcomes of a pregnancy that may influence the subsequent mental health of the mother. Women's experiences of live births are generally claimed to carry minimal risks of mental health problems. Evidence from cross-sectional studies, however, suggest an increasing prevalence of mental health disorders for parents of live infants (4). A mother may decide to avoid a birth through abortion, she may give a child up for adoption, or a child may die either in pregnancy or shortly thereafter. The fourth possibility is of a subsequent birth impacting on the mental health and wellbeing of the mother. For each of the above outcomes, there is a need to know more about their medium and long-term consequences for the mothers' mental health.

Giving up a child for adoption may relate to maternal mental health but has frequently been overlooked due to lack of appropriate data. Of the ten studies examining the association between adoption and maternal mental health outcomes, one longitudinal study found worse outcomes (5) whereas other cross-sectional studies have reported mixed outcomes. Changes in mothers' socio-economic circumstances and having an unplanned child may lead to a decision to relinquish a baby for adoption (6). This decision to relinquish may precipitate maternal mental health problems (2). Moreover, giving a baby up for adoption may be associated with social stigma (7) and may increase the risk of maternal distress. A handful of studies have suggested that giving up a child for adoption may be associated with an increased risk of maternal psychopathology including depression (5). However, distress prior to giving up a child for adoption may also contribute to poor maternal mental health.

Findings from cross-sectional studies suggest that termination of pregnancy (ToP) may lead to increased risks of anxiety, depression and other adverse mental health outcomes (8). Other studies suggest that ToP may be transient and lead only to short-term effects (9). Studies using longitudinal data have suggested an association of ToP with anxiety, avoidance behaviours, feelings of guilt, shame (10) and depression (1). However, one longitudinal study found only transient depression lasting for a brief period after ToP (11). It has also been suggested that ToP itself does not necessarily predict mental health problems, rather it may be indirectly influenced by altered contraceptive behaviour due to pre-existing disorders (12).

Cross-sectional evidence suggests foetal loss (13) may also lead to an increase in mental health problems (14). However, a case-control study has found a weak association between pregnancy loss and depression (15). A handful of longitudinal studies have documented the risk of depression anxiety and illicit drug use disorders (1) associated with a pregnancy loss but showed mixed effects for womenwho have miscarried (16). Some reviews have reported that pregnancy losses may predict anxiety (16) depression and posttraumatic stress disorders of the bereaved mothers (17). It has also been suggested that pre-existing mental health problems such as affective disorders, substance (18) and alcohol (19) use disorders reciprocally predict pregnancy losses.

Neonatal, infant and/or child death could lead to long-lasting mental health problems. This may continue to affect the overall health of mothers (13) with concurrent anxiety, depression and psychiatric illnesses (20) with more severe symptoms immediately following bereavement (21) than later in life (22). Data from two Australian matched case-control studies have documented high levels of anxiety and depression after two months (24) and psychological distress at 30 months (23). The severity of symptoms of mental illness appears to be more intense in the

DOI: http://dx.doi.org/10.4314/ejhs.v27i4.6 
early phases of bereavement (22). The risk of hospitalization appears to increase in the first five years (25) and up to 12-15 years (26) after a child death. Four longitudinal studies investigating the maternal mental effects of a child death have reported mixed outcomes - three of which are short-term (22) while the remaining one is longterm mental health effects (25).

Generally, the evidence suggests that pregnancy-related losses may cause maternal mental health problems. However, psychological reactions may be of limited duration and those experiencing a child loss may readjust to normal life with significant improvement overtime. This may partly be due to subsequent live births that possibly contribute to recovery for bereaved families. That is, perinatal loss related grief responses of parents may differ overtime, particularly in the context of such a salient event as a new pregnancy.

The hypothesis that adverse pregnancy outcomes may lead to maternal mental health problems is qualified by the observation that a number of other factors may confound this association. Social deprivation including poverty (27), teenage pregnancy (28), smoking (28) and alcohol use (19) are believed to have been associated with adverse pregnancy outcomes which may in turn contribute to the existing mental health problems. It is also possible that mental health problems experienced after prior adverse pregnancy outcomes may be influenced by the birth of a new child.

There is a need to know more about how women react to different pregnancy outcomes. This may improve our insight on the potential mental health impact of birth-related traumas on medium and long-term perspectives. It adds to the literature by describing the distal influences of different previous pregnancy outcomes on the mothers' mental health status. Moreover, none of the studies so far has assessed the mental health of mothers who had had their child adopted out. In this article, we use data from a first obstetrical clinic visit. Mothers were followed up to 14 years after the birth of a child to determine whether adverse pregnancy outcomes impacted on the mental health of mothers.

\section{METHODS}

Study participants: This study uses data from the Mater-University of Queensland Study of Pregnancy (MUSP). MUSP is a prospective pre-birth cohort which has included a sample of all consecutive women presenting at the Mater Misericordiae Hospital for their first obstetrical visit (FCV). Usually recruitment is in the first trimester of pregnancy (29). A total of 8556 mothers were initially approached, 8458 accepted the invitation, and 7223 gave birth to a live, singleton baby at the study hospital. Thus, 7223 constitute the cohort for follow-up. The study recruited pregnant women at their FCV, and additional data were collected from $4403(61 \%)$ at the 14-year follow-up. The mean age of the women at their FCV was 25.04 years. Ethical clearance for each phase was obtained from the relevant ethics committee of The University of Queensland, and all participants provided written informed consent at each phase of data collection.

Nurses, as part of the routine first obstetrical visit, collected information detailing the medical and obstetric history of mothers at first obstetric assessment. Medical details of previous pregnancies and their outcomes were in the obstetric data sheet and taken by nurses who recorded the womens' reproductive history. About 36\% ( $\mathrm{n}=2460)$ women were having their first pregnancy at the FCV. The remaining women had had at least one prior pregnancy. The current analysis included 4403 women for whom data were available both at FCV and the 14-year follow-up.

Measurements: Data on anxiety and depressive symptoms of mothers were collected by using the two seven-item sub-scales of the DelusionsSymptoms-States Inventory (DSSI) (30) at FCV and 14-year follow-up. Individual numbers of symptoms were counted to provide dichotomous outcome variables of symptoms of anxiety and depression (Yes/No). The "caseness" for symptoms of anxiety and depression was determined by using four symptoms cut-offs (30). Women with 4+ symptoms were classified as having had symptoms of anxiety and depression. The DSSI is not a clinical diagnostic tool but has been validated and found to be a reliable scale for screening and measuring psychiatric disturbances (31).

Predictors: Mothers were asked about the number and outcome of each prior pregnancy at the time of

DOI: http://dx.doi.org/10.4314/ejhs.v27i4.6 
their first obstetrical visit for their current pregnancy. Mothers with a prior history of miscarriage, ectopic pregnancy and stillbirth were grouped as were those who had had a miscarriage (32). Those with any neonatal, infant and child deaths were classified as having experienced a child death. There was hierarchical allocation for multiple outcomes with ToP and deaths given priority. The current analysis grouped women according to those who had had no prior pregnancy, had given birth only to live children, or had a history of previous miscarriages, ToP, giving a baby up for adoption and any deaths.

Confounders: Information on maternal sociodemographic characteristics was collected both at FCV and the 14-year follow-up. Maternal age (coded as: $13-19$ (reference)/20-34/35+ years) and education (coded as: incomplete (reference)/complete/post high school) were measured at FCV and used both at the FCV and the 14-year follow-up. Maternal marital status (coded as: single (reference)/living to gether/married/separated-divorced-and-widowed)

was measured at FCV and the 14-year follow-up. Annual family income was measured at FCV (coded as: $\geq A U \$ 10,399$ (reference)/ $\leq$ AU \$10,400) and 14year follow-up (coded as: $\geq A U \$ 20,799$ (reference)/ $\leq \mathrm{US} \$ 20,800)$.

Analysis: We included 4403 women with complete data at both FCV and at 14-year follow-up. Descriptive analysis was done to explore the distribution of study variables. Past obstetrical history was used to predict current (FCV) and 14year levels of DSSI symptoms. Mothers with no previous pregnancies were the reference group. Logistic regression was used for dichotomous outcomes (Yes/No). The goodness-of-fit chi-squared test and maximum likelihood estimate were used to assess statistical significance and model fit, respectively.

To identify potential confounding, stepwise forward logistic regression was employed. Confounders were identified and retained if respective $p$-value was $<.05$. Socio-demographic characteristics were fitted separately for symptoms of anxiety and depression at each phase. The odds ratios (ORs) with 95\% confidence intervals (95\% CIs) was used. The maximum likelihood ratio was used to test for model fit. Significance of association was set at $\mathrm{p}<0.05$. Stata version 13 statistical package for windows was used for the analysis. Assuming missing data was missing at random (33), we conducted multiple imputations for missingness. Data were imputed for all missing data points from both FCV and the 14year follow-up by using Multivariate Imputations by Chained Equation. We used 20 cycles to generate 20 imputed datasets for the 4403 sample of mothers. We repeated the analysis with the imputed dataset and did not detect any significant difference from the non-imputed dataset. We then used the non-imputed dataset for our final analysis. Pairwise comparison was done after adjustment.

\section{RESULTS}

A total of 9029 prior pregnancy outcomes were recorded in the obstetric data sheet. About $72 \%(\mathrm{n}=$ 6469) of the total pregnancies were live births; followed by $17.9 \%(n=1616)$ miscarriage; $6.0 \%(n$ $=535)$ ToP; $1.76 \%(\mathrm{n}=159)$ adoption; $1.06 \%(\mathrm{n}=$ 96) stillbirth; $0.97 \%(\mathrm{n}=88)$ neonatal death; $0.36 \%(\mathrm{n}$ $=33$ ) infant death; and $0.33 \%(n=30)$ child death. Some mothers had experienced repeated (i.e., similar or different) adverse birth outcomes. Mothers with a history of having given a child for adoption were excluded from the final analysis due to small number of cases. We created a variable "prior pregnancy outcome" which comprised of five categories with combined previous pregnancy outcomes: neverpregnant before, only live births, a prior miscarriage or ToP or death as the main predictor variable.

The majority of women in the study were in the 20-34 age group (Table 1). Understandably, miscarriages and deaths appeared to be disproportionately reported by the older women in the study. Women who had had not completed high school appeared to report higher rates of miscarriage and death. Moreover, those mothers who were married reported having more often experienced these adverse pregnancy outcomes, presumably because they were older. Presumably, mothers from economically disadvanteged families had more likehood of adverse prior pregnancy outcomes (Table 1).

DOI: http://dx.doi.org/10.4314/ejhs.v27i4.6 
Table 1: Descriptive characteristics of variables in the study

\begin{tabular}{|c|c|c|c|c|c|c|}
\hline \multirow[t]{2}{*}{ Socio-demographics } & \multicolumn{5}{|c|}{ History of pregnancy outcomes $(n=4403)$} & \multirow[t]{2}{*}{$\mathbf{X}^{2}(\mathbf{p}$-value $)$} \\
\hline & $\begin{array}{l}\text { Non-pregnant } \\
(\mathrm{n}=1644)\end{array}$ & $\begin{array}{l}\text { All live births } \\
(\mathrm{n}=1676)\end{array}$ & Miscarriages $(n=739)$ & ToP $(n=260)$ & $\begin{array}{l}\text { Deaths } \\
(\mathrm{n}=84)\end{array}$ & \\
\hline \multicolumn{7}{|l|}{ Age (years) } \\
\hline $13-19$ & 30.5 & 3.1 & 5.4 & 14.2 & 14.3 & $667.5(<.0001)$ \\
\hline $20-34$ & 68.7 & 91.1 & 84.6 & 83.8 & 70.2 & \\
\hline $35+$ & 0.8 & 5.8 & 10.0 & 2.0 & 15.5 & \\
\hline \multicolumn{7}{|l|}{ Education (high school) } \\
\hline Incomplete & 13.1 & 17.2 & 19.9 & 14.6 & 22.6 & $183.1(<.0001)$ \\
\hline Complete & 65.5 & 64.5 & 62.5 & 68.5 & 60.7 & \\
\hline Post & 21.4 & 18.3 & 20.3 & 16.9 & 16.7 & \\
\hline \multicolumn{7}{|l|}{ Marital status } \\
\hline Single & 18.6 & 1.7 & 3.2 & 4.2 & 3.6 & $420.9(<.0001)$ \\
\hline Living together & 11.5 & 6.7 & 9.7 & 17.3 & 8.3 & \\
\hline Married & 68.7 & 89.6 & 83.6 & 63.8 & 80.9 & \\
\hline Separated/widowed/divorced & 1.2 & 2.0 & 3.5 & 4.7 & 7.2 & \\
\hline \multicolumn{7}{|l|}{ Family income } \\
\hline$\leq \$ 10,399$ & 29.7 & 27.2 & 28.4 & 35.0 & 35.5 & $183.2(<.0001)$ \\
\hline$\geq \$ 10,400$ & 70.3 & 72.8 & 71.6 & 65.0 & 64.5 & \\
\hline \multicolumn{7}{|l|}{ Depressive symptoms at FCV } \\
\hline Yes & 4.2 & 5.5 & 4.6 & 6.2 & 8.3 & $6.1(.195)$ \\
\hline No & 95.8 & 94.5 & 95.4 & 93.8 & 91.7 & \\
\hline \multicolumn{7}{|c|}{ Depressive symptoms at 14 -year } \\
\hline Yes & 7.2 & 8.2 & 10.6 & 9.2 & 14.3 & $11.7(.02)$ \\
\hline No & 92.8 & 91.8 & 89.4 & 90.8 & 84.7 & \\
\hline \multicolumn{7}{|l|}{ Anxiety at FCV } \\
\hline Yes & 3.8 & 10.5 & 12.3 & 15.4 & 17.9 & $9.1(.05)$ \\
\hline No & 96.2 & 89.5 & 87.7 & 84.6 & 81.1 & \\
\hline \multicolumn{7}{|l|}{ Anxiety at 14 -year } \\
\hline Yes & 17.5 & 18.1 & 21.5 & 21.5 & 22.6 & $7.9(.09)$ \\
\hline No & 82.5 & 81.9 & 79.5 & 79.5 & 77.4 & \\
\hline
\end{tabular}

DOI: http://dx.doi.org/10.4314/ejhs.v27i4.6 
Table 2: Unadjusted (UOR) and adjusted odds ratios (AOR) for anxiety and depression (4+ symptoms cut-offs) with 95\%CI among MUSP mothers at FCV, Brisbane, Australia

\begin{tabular}{|c|c|c|c|c|c|c|c|c|}
\hline \multirow[b]{2}{*}{ Prior pregnancy outcome $(n=4403)$} & \multicolumn{4}{|c|}{ Anxiety at FCV } & \multicolumn{4}{|c|}{ symptoms of depression at FCV } \\
\hline & Yes $(\%)$ & No $(\%)$ & $\begin{array}{c}\text { UOR } \\
(95 \% \mathrm{CI})\end{array}$ & $\begin{array}{c}\text { AOR } \\
(95 \% \mathrm{CI})\end{array}$ & Yes $(\%)$ & No $(\%)$ & $\begin{array}{c}\text { UOR } \\
(95 \% \mathrm{CI})\end{array}$ & $\operatorname{AOR}(95 \% \mathrm{CI})$ \\
\hline Never pregnant $(n=1644)$ & $190(11.6)$ & $\begin{array}{c}1454 \\
(89.4)\end{array}$ & Ref & Ref & $69(4.2)$ & $\begin{array}{l}1575 \\
(95.8)\end{array}$ & Ref & Ref \\
\hline All live $(\mathrm{n}=1676)$ & $176(10.5)$ & $\begin{array}{l}1500 \\
(89.5)\end{array}$ & $.89(.72-1.12)$ & $\begin{array}{c}1.13(.87- \\
1.46)\end{array}$ & $92(5.5)$ & $\begin{array}{l}1584 \\
(94.5)\end{array}$ & $\begin{array}{c}1.33(.96- \\
1.83)\end{array}$ & $2.24(.81-3.20)$ \\
\hline Miscarriage $(\mathrm{n}=739)$ & $91(12.3)$ & $648(87.7)$ & $\begin{array}{c}1.10(.82- \\
1.40)\end{array}$ & $\begin{array}{c}1.19(.88- \\
1.61)\end{array}$ & $34(4.6)$ & $705(95.4)$ & $\begin{array}{c}1.10(.72- \\
1.68)\end{array}$ & $1.54(.93-2.53)$ \\
\hline Termination of pregnancy $(n=260)$ & $40(15.4)$ & $220(84.6)$ & $\begin{array}{c}1.39(.96- \\
2.01)\end{array}$ & $\begin{array}{c}1.37(.92- \\
2.04)\end{array}$ & $16(6.2)$ & $244(93.8)$ & $\begin{array}{c}1.50(.85- \\
2.62)\end{array}$ & $1.59(.86-2.95)$ \\
\hline Deaths $(n=84)$ & $15(17.9)$ & $69(81.1)$ & $\begin{array}{c}1.66(.83- \\
2.97)\end{array}$ & $\begin{array}{c}1.64(.88- \\
3.10)\end{array}$ & $7(8.3)$ & 77 (91.7) & $\begin{array}{c}2.10(.92- \\
4.67)\end{array}$ & $2.58(.90-6.31)$ \\
\hline
\end{tabular}

Adjusted for age, education, marital status and family income. 
Table 3: Unadjusted (UOR) and adjusted odds ratios (AOR) for anxiety and depression (4+ symptoms cut-offs) with 95\%CI among MUSP mothers at 14-year follow-up, Brisbane, Australia

\begin{tabular}{|c|c|c|c|c|c|c|c|c|}
\hline \multirow{2}{*}{$\begin{array}{l}\text { Prior pregnancy outcome } \\
(n=4403)\end{array}$} & \multicolumn{4}{|c|}{ Anxiety at 14-year } & \multicolumn{4}{|c|}{ symptoms of depression at 14-year follow-up } \\
\hline & Yes $(\%)$ & No $(\%)$ & $\begin{array}{c}\text { UOR } \\
(95 \% \mathrm{CI})\end{array}$ & $\begin{array}{c}\text { AOR* } \\
(95 \% \mathrm{CI})\end{array}$ & $\begin{array}{l}\text { Yes } \\
(\%)\end{array}$ & No $(\%)$ & $\begin{array}{c}\text { UOR } \\
(95 \% \mathrm{CI})\end{array}$ & $\operatorname{AOR}^{*}(95 \% \mathrm{CI})$ \\
\hline Never pregnant $(\mathrm{n}=1644)$ & $\begin{array}{c}288 \\
(17.5)\end{array}$ & $\begin{array}{c}1356 \\
(82.5)\end{array}$ & Ref & Ref & $\begin{array}{c}118 \\
(7.2)\end{array}$ & $\begin{array}{l}1526 \\
(91.8)\end{array}$ & Ref & Ref \\
\hline All live $(n=1676)$ & $\begin{array}{c}304 \\
(18.1)\end{array}$ & $\begin{array}{l}1372 \\
(81.9)\end{array}$ & $\begin{array}{c}1.1(.87- \\
1.25)\end{array}$ & $1.14(.92-1.40)$ & $\begin{array}{l}138 \\
(8.2)\end{array}$ & $\begin{array}{l}1538 \\
(91.8)\end{array}$ & $\begin{array}{l}1.16(.90- \\
1.50)\end{array}$ & $1.14(.99-1.81)$ \\
\hline Miscarriage $(\mathrm{n}=739)$ & $\begin{array}{c}159 \\
(21.5)\end{array}$ & $580(79.5)$ & $1.4(1.1-1.6)$ & $1.30(1.1-1.66)$ & $\begin{array}{c}78 \\
(10.6)\end{array}$ & $661(89.4)$ & $\begin{array}{c}1.53(1.10- \\
2.10)\end{array}$ & $1.70(1.21-2.39)$ \\
\hline $\begin{array}{l}\text { Termination of pregnancy }(n= \\
260)\end{array}$ & $56(21.5)$ & $204(79.5)$ & $\begin{array}{c}1.3(.94- \\
1.78)\end{array}$ & $1.19(.83-1.69)$ & $24(9.2)$ & $236(90.8)$ & $\begin{array}{l}1.32(.80- \\
2.10)\end{array}$ & $1.37(.84-2.24)$ \\
\hline Deaths $(n=84)$ & $19(22.6)$ & $65(77.4)$ & $\begin{array}{l}1.4(.81- \\
2.33)\end{array}$ & $1.04(.57-2.89)$ & $\begin{array}{c}12 \\
(14.3)\end{array}$ & $72(85.7)$ & $\begin{array}{l}2.16(1.10- \\
4.10)\end{array}$ & $2.12(1.06-4.25)$ \\
\hline
\end{tabular}

Adjusted for age, education, marital status and family income. *Adjusted for anxiety and Depressive symptoms at FCV 
As the numbers of women who report a previous pregnancy termination and death were limited, some of the estimates have wide confidence intervals (Table 2). After adjustment for the mothers, age, education and marital status, we found that women who had only ever had a live birth experienced symptoms of anxiety and depression at about the same rate as women who had never previously been pregnant. Similarly, women who had had a previous miscarriage (and were currently pregnant) appeared to experience levels of anxiety and depression at the same level as those experienced by women who never had a past pregnancy. Controlling for anxiety at FCV did not appear to change the direction and strength of association between adverse pregnancy outcomes and anxiety at 14-year follow-up. Some 260 women reported that they had previously had a termination of a pregnancy. For women who had previously had a termination and were currently pregnant, there was no evidence of elevated levels of anxiety and/or depression. Much the same was the case for women who reported experiencing a previous child death. A caveat here is to emphasise the small numbers involved and the high point estimate particularly for symptoms of depression.

The effect sizes and the directions of association of prior adverse pregnancy outcomes on maternal mental health were similar at both time points (Table 3). After adjustment for age, education and marital status, mothers who had only ever had a live birth experienced symptoms of anxiety and depression at about the same rate as women who had never previously been pregnant. Mothers who had had a previous miscarriage experienced statistically significant and higher levels of symptoms of anxiety and depression than those mothers who never had a past pregnancy. A history of a previous termination of a pregnancy was not associated with any significantly elevated level of anxiety and depressive symptoms. Depressive symptoms level was also found to be significantly higher for mothers who report experiencing a previous child death. Adjustments for the background characteristics at FCV appeared to reduce the effect sizes. However, controlling for depressive symptoms at FCV did not significantly change the direction and strength of association between adverse outcomes and depressive symptoms at 14year follow-up (Table 3). This analysis also revealed that younger women, those who had had completed or had a post high school education, those who were living together with a partner, were married and were reporting high family income were at lower risk of symptons of anxiety and depression both at the FCV and the 14-year follow-up. Apparently, poor metal health status at FCV significantly predicted synptoms of anxiety and depression at the 14- year follow-up (data not shown). Pairwise comparisons of adjusted models revealed non-significant differences for levels of symptoms of anxiety and depressiion of mothers with prior adverse pregnancy outcomes and those women with only prior live births. Analysis with imputed dataset suggested that missing values were not associated with biased estimates of association.

\section{DISCUSSION}

Our study participants were drawn from a large population-based longitudinal study that initially recruited a sample of pregnant women who were somewhat skewed towards lower socio-economic characteristics. We included women who had not previously been pregnant and those mothers who had given birth to a live children as comparison groups to explore the effects of other adverse outcomes.

Despite a growing interest in exploring the mental health status of women with prior adverse pregnancy outcomes, available evidence has demonstrated mixed short-term maternal mental health consequences, and little is known about whether having a new pregnancy and live child impact on maternal anxiety and depressive symptoms levels. The adjusted analyses suggest four main findings. Firstly, we noted the nonsignificant associations between previous adverse pregnancy outcomes and anxiety and depressive symptoms at FCV for currently pregnant women. Secondly, despite having a live child,women who had had previous miscarriage appeared to experience higher levels of anxiety and symptoms

DOI: http://dx.doi.org/10.4314/ejhs.v27i4.6 
of depression at the 14-year follow-up. Thirdly, women who reported experiencing a previous child death revealed significant level of symptoms of depression at the 14-year follow-up, but curiously not at the FCV. Lastly, a pairwise comparison of adjusted model shows that women who had had a previous adverse outcome had nonsignificantly higher risks of anxiety and depression than women with only prior live births at FCV (at the current pregnancy) and 14-year follow-up.

Statistically non-significant associations were observed between a prior $\mathrm{ToP}$ and maternal mental health outcomes at FCV and the 14-year follow-up. These findings are consistent with other studies demonstrating that ToP was not statistically associated with clinically defined depression (34) and depression related psychiatric treatment (35). However, they contradict with the findings of other studies (1) which have reported significant associations between ToP and adverse mental health outcomes. The possible reasons for these differences could be differences in study sample characteristics where our samples were population-based samples whereas most prior studies draw their samples from clinics. The other possibility is the presence of a live birth with better health outcomes. The causal link between ToP and symptoms of depression remains inconclusive (11). It has been suggested that ToP does not directly affect the mental health status of mothers. Instead, it has an indirect effect by influencing the contraceptive behaviour of women such that unintended pregnancy with live births can lead to symptoms of depression (12) via adverse reactions of a live child (32). Though reasonable length of time had passed since ToPs occurred, there was a possibility that some women would experience a continuation of prior mental health problems from these ne ative life events (36) which can lead to posttraumatic stress disorder (37).

The non-significant association between prior miscarriage and maternal poor mental health at FCV (during pregnancy) is consistent with prior studies showing rapid improvements of mental health (38) following an adverse pregnancy outcome. On the other hand, some longitudinal studies (1) suggest there is a persistent association with symtoms of depression regardless of a preexisting psychiatric history, pregnancy stress and poor social support (39) in bereaved mothers (14). This reinforces our finding at the 14-year followup. Here of course, we might speculate that being pregnant may improve the mothers' mood, and that this effect dissipates subsequently. However, the findings from previous studies $(10,16,38)$ suggest no such associations. Our findings may contribute evidence concerning whether symptoms of depression after miscarriage continued into the next pregnancy or was resolved by a new pregnancy (39). Pregnancy may enhance the mothers' mood in the context of a pregnancy loss, or when negative life events (38) may affect the mental health of a woman. These findings imply that having a new pregnancy improves maternal mental health, but perhaps for a short period of time. We noted the significantly higher levels of anxiety and symptoms of depression at the 14-year follow-up in general, and for women who had previously miscarried in particular.

Our finding relating to previous death of a child and maternal mental health outcomes showed non-significant associations at the current pregnancy. However, death of a child was associated with maternal symptoms of depression at the 14-year follow-up. Contrary to our findings at the FCV, death of a child has been reported to have intense effects in early phases of bereavement (21) abating in later stages of life (22). Moreover, evidence from longitudinal studies has demonstrated that symptoms of depression are more common in early phases of bereavement (22) with symptoms declining over time. Consistent with the findings at the 14-year follow-up, other literature (1) has found psychological illnesses $(22,26)$, depression (24) and mental health-related hospitalization (25) rates were higher for mothers with a history of child death. These associations may also relate to other lifestyle-related factors. For instance, heavy drinking is most often experienced by bereaved parents (40). Indeed, death-related mental health problems are suggested to be causal because they are independent of prior mental health disorders (22). Moreover, significant association at later

DOI: http://dx.doi.org/10.4314/ejhs.v27i4.6 
stages of life may suggest newer and/or recurrence cases.

Our findings need to be considered in the context of some limitations. Although the findings remain significant after controlling for potential confounders, the mechanisms of associations remain unclear. This study does not establish causal associations between pregnancy outcomes and subsequently occurring anxiety and depressive symptoms. These associations may be due to unmeasured confounders, such as underlying poverty, that potentially have adverse effects on pregnancy outcomes and mental health problems. Furthermore, we could not delineate the time that elapsed between a particular pregnancy outcome and the FCV since these outcomes were maternal retrospective reports. Moreover, no data exist on prior mental health of mothers, and it was not possible to rule out whether pre-pregnancy mental health status contributed to anxiety and depressive symptoms at FCV, or indeed whether pre-existing anxiety and/or depression contributed to the pregnancy loss. Also, DSSI may not be an ideal tool to assess clinical level anxiety and depression. However, significant associations between history of ToPs and deaths, and maternal mental health status at 14-year follow-up after controlling for anxiety and depressive symptoms at FCV may suggest robust prediction of prior adverse pregnancy outcomes than other confounders on long-term basis. Finally, the potential lack of representativeness of the sample due to selection of women from only one institution might have limited the generalizability of the findings.

Despite these limitations, this study has addressed the effects of adverse pregnancy outcomes on maternal anxiety and depressive symptoms at two stages over the reproductive life span. There is a need to determine whether a new pregnancy improves maternal mental health regardless of prior adverse pregnancy outcomes. This study is one of the few attempts so far that have investigated long-term mental health problems which may follow an adverse pregnancy outcome. Moreover, it controls for earlier mental health status while predicting longer-term outcomes. This may improveour insight into potential mental health impacts of birth-related traumas on medium and long-term perspectives. The mean age of these women at the 14-year assessment was nearly 40 years. This amy provide some insight into the mental health matters related to adverse pregnancy outcomes for women in this age group.The effect of attrition was controlled by limiting the analysis to a defined cohort of mothers at FCV and the 14- year follow-up. Thus, any differences in outcomes would not account for changes in sample size. Moreover, multiple imputations were undertaken to detect the influence of missingness.

In summary, though the underlying mechanisms of associations are not clear, different adverse pregnancy outcomes are believed to increase the risk for a wide range of maternal mental health problems. For instance, miscarriage might be thought of as a very stressful event, which might trigger adverse psychological reactions. It is difficult to know whether a new pregnancy after the loss of a child may improve the mental health of mothers. Further research should concentrate on underlying causes, trajectories and mechanisms of associations of adverse pregnancy outcomes and maternal mental health controlling for potential confounders and pre-existing mental health disorders.

New pregnancies may appear to benefit the mental health of women who have had prior adverse pregnancy outcomes. However, whether having a new pregnancy ensures enduring positive impact for maternal mental health after a prior miscarriage (pregnancy loss) and child death does not provide a definitive answer and needs robust evidence.

\section{ACKNOWLEDGEMTS}

We would like to extend our acknowledgments to the MUSP mother-child pairs, National Health and Medical Research Council and Australian Research Council for subsequent funding of the MUSP study.

DOI: http://dx.doi.org/10.4314/ejhs.v27i4.6 


\section{REFERENCES}

1. Dingle K, Alati R, Clavarino A, Najman JM, Williams GM. Pregnancy loss and psychiatric disorders in young women: an Australian birth cohort study. The British Journal of Psychiatry. 2008;193(6):455-60.

2. Steinberg JR, Jordan B, Wells ES. Science prevails: abortion and mental health. Contraception. 2009;79(2):81-3.

3. Coleman PK, Coyle CT, Shuping M, Rue VM. Induced abortion and anxiety, mood, and substance abuse disorders: Isolating the effects of abortion in the national comorbidity survey. Journal of psychiatric research. 2009;43(8):770-6.

4. O'Donnell M, Anderson D, Morgan VA, Nassar N, Leonard HM, Stanley FJ. Trends in pre-existing mental health disorders among parents of infants born in Western Australia from 1990 to 2005. Med J Aust. 2013;198(9):485-8.

5. Glidden LM, Jobe BM. The longitudinal course of depression in adoptive and birth mothers of children with intellectual disabilities. Journal of Policy and Practice in Intellectual Disabilities. 2006;3(2):139-42.

6. Najman JM, Morrison J, Keeping JD, Andersen MJ, Williams GM. Social factors associated with the decision to relinquish a baby for adoption. Community health studies. 1990;14(2):180-9.

7. Kressierer DK, Bryant CD. Adoption as deviance: Socially constructed parent-child kinship as a stigmatized and legally burdened relationship. Deviant Behavior. 1996;17(4):391-415.

8. Coleman PK. Abortion and mental health: quantitative synthesis and analysis of research published 1995-2009. The British Journal of Psychiatry. 2011;199(3):180-6.

9. Steinberg JR, Trussell J, Hall KS, Guthrie K. Fatal flaws in a recent meta-analysis on abortion and mental health. Contraception. 2012;86(5):430-7.

10. Broen AN, Moum T, Bødtker AS, Ekeberg $\varnothing$. The course of mental health after miscarriage and induced abortion: a longitudinal, five-year follow-up study. BMC medicine. 2005;3(1):18.

11. Taft AJ, Watson LF. Depression and termination of pregnancy (induced abortion) in a national cohort of young Australian women: the confounding effect of women's experience of violence. BMC Public Health. 2008;8(1):75.

12. Steinberg JR, Rubin LR. Psychological Aspects of Contraception, Unintended Pregnancy, and Abortion. Policy insights from the behavioral and brain sciences. 2014;1(1):239-47.

13. Lassi ZS, Majeed A, Rashid S, Yakoob MY, Bhutta ZA. The interconnections between maternal and newborn health-evidence and implications for policy. The Journal of Maternal-Fetal \& Neonatal Medicine. 2013;26(sup1):3-53.

14. Gold KJ, Boggs ME, Muzik M, Sen A. Anxiety disorders and obsessive compulsive disorder 9 months after perinatal loss. General hospital psychiatry. 2014;36(6):650-4.

15. Howard LM, Kirkwood G, Latinovic R. Sudden infant death syndrome and maternal depression. The Journal of clinical psychiatry. 2007;68(8):1279-83.

16. Geller PA, Kerns D, Klier CM. Anxiety following miscarriage and the subsequent pregnancy: a review of the literature and future directions. Journal of psychosomatic research. 2004;56(1):35-45.

17. Frost M, Condon JT. The psychological sequelae of miscarriage: a critical review of the literature. Australasian Psychiatry. 1996;30(1):54-62.

18. Gold KJ, Dalton VK, Schwenk TL, Hayward RA. What causes pregnancy loss? Preexisting mental illness as an independent risk factor. General hospital psychiatry. 2007;29(3):207-13.

19. Bailey BA, Sokol RJ. Prenatal alcohol exposure and miscarriage, stillbirth, preterm delivery, and sudden infant death syndrome. Alcohol Research \& Health. 2011;34(1):86.

20. Sutan R, Amin RM, Ariffin KB, Teng TZ, Kamal MF, Rusli RZ. Psychosocial impact of mothers with perinatal loss and its contributing factors: an insight. Journal of Zhejiang University Science. 2010;11(3):209-17.

21. Parkes CM. Coping with loss: Bereavement in adult life. BMJ: British Medical Journal. 1998;316(7134):856.

22. Stroebe M, Schut H, Stroebe W. Health outcomes of bereavement. The Lancet. 2007;370(9603):1960-73.

23. Boyle FM, Vance JC, Najman JM, Thearle MJ. The mental health impact of stillbirth, neonatal death or SIDS: prevalence and patterns of distress among mothers. Social science \& medicine). 1996;43(8):127382.

24. Vance J, Foster W, Najman J, Embelton G, Thearle M, Hodgen F. Early parental responses to sudden infant death, stillbirth or neonatal death. The Medical Journal of Australia. 1991;155(5):292-7.

25. Ferri CP, Mitsuhiro SS, Barros MC, Chalem E, Guinsburg R, Patel V, et al. The impact of maternal experience of violence and common mental disorders on neonatal outcomes: a survey of adolescent mothers in Sao Paulo, Brazil. BMC Public Health. 2007;7:209.

26. Dyregrov AD, Kari. Long-term impact of sudden infant death: A 12-to 15-year follow-up. Death studies. 1999;23(7):635-61.

DOI: http://dx.doi.org/10.4314/ejhs.v27i4.6 
27. Arck PC, Rücke M, Rose M, Szekeres-Bartho J, Douglas AJ, Pritsch M, et al. Early risk factors for miscarriage: a prospective cohort study in pregnant women. Reproductive biomedicine online. 2008;17(1):101-13.

28. Hure AJ, Powers JR, Mishra GD, Herbert DL, Byles JE, Loxton D. Miscarriage, preterm delivery, and stillbirth: large variations in rates within a cohort of Australian women. PLoS One. 2012;7(5):37109.

29. Najman JM, Alati R, Bor W, Clavarino A, Mamun A, McGrath JJ, et al. Cohort profile update: The Mater-University of queensland study of pregnancy (MUSP). International journal of epidemiology. 2014;44(1):78-f.

30. Bedford A, Foulds GA, Sheffield BF. A new personal disturbance scale (DSSI/sAD). Br J Soc Clin Psychol. 1976;15(4):387-94.

31. Cox JL, Holden JM, Sagovsky R. Detection of postnatal depression. Development of the 10-item Edinburgh Postnatal Depression Scale. The British journal of psychiatry. 1987;150(6):782-6.

32. Fergusson DM, Horwood LJ, Boden JM. Abortion and mental health disorders: evidence from a 30-year longitudinal study. The British Journal of Psychiatry. 2008;193(6):444-51.

33. Sterne JA, White IR, Carlin JB, Spratt M, Royston $\mathrm{P}$, Kenward MG, et al. Multiple imputation for missing data in epidemiological and clinical research: potential and pitfalls. BMJ. 2009;338:b2393.
34. Schmiege S, Russo NF. Depression and unwanted first pregnancy: longitudinal cohort study. BMJ. 2005;331(7528):1303.

35. Fergusson DM. Abortion and mental health. The Psychiatrist. 2008;32(9):321-4.

36. Keeping J, Najman J, Morrison J, Western J, Andersen M, Williams G. A prospective longitudinal study of social, psychological and obstetric factors in pregnancy: response rates and demographic characteristics of the 8556 respondents. British journal of obstetrics and gynaecology. 1989;96(3):289-97.

37. Rue VM, Coleman PK, Rue JJ, Reardon DC. Induced abortion and traumatic stress: A preliminary comparison of American and Russian women. Medical Science Monitor. 2004;10(10):SR5-SR16.

38. Rowlands I, Lee C. Adjustment after miscarriage: Predicting positive mental health trajectories among young Australian women. Psychology, health \& medicine. 2010;15(1):34-49.

39. Klier CM, Geller P, Ritsher J. Affective disorders in the aftermath of miscarriage: A comprehensive review. Archives of Women's Mental Health. 2002;5(4):129-49.

40. Vance J, Najman J, Boyle F, Embelton G, Foster $\mathrm{W}$, Thearle M. Alcohol and drug usage in parents soon after stillbirth, neonatal death or SIDS. Journal of paediatrics and child health. 1994;30(3):269-72. 